\title{
The effect of acetazolamide on breath holding at high altitude
}

\author{
S.C. Morrissey, K. Keohane and J.H. Coote \\ Department of Physiology, The Medical School, University of Birmingham, Edgbaston, Birmingham B15 2TH. \\ $U K$.
}

\begin{abstract}
Summary: The effect of altitude and acetazolamide on breath holding was studied in 20 individuals. Breath holding time was reduced progressively during ascent. There was an additional reduction in the acetazolamide group at low but not at high altitude. The initial difference between the two groups may have been related to a lower CSF pH when on acetazolamide. At high altitude the finding of similar breath holding times in the two groups may have been due to acclimatization in the placebo group.
\end{abstract}

\section{Introduction}

Breath holding to breaking point is influenced by a wide variety of factors. Schneider ${ }^{1}$ observed that maximal breath holding was reduced by acute exposure to high altitude and further reduced during the next few days of adaptation. In the absence of hypoxia, Godfrey \& Campbell ${ }^{2}$ proposed that there were two dynamic components to the control of breath holding, namely, rising $\mathrm{PCO}_{2}$ and the duration of absence of normal respiratory movement.

This study was designed to assess the effect of rapid ascent to high altitude and the influence of acetazolamide on breath holding. It is thought that the respiratory response to the lower arterial $\mathrm{pH}$ induced by acetazolamide is an important factor in the prophylaxis of acute mountain sickness. ${ }^{3}$

\section{Materials and methods}

Twenty normal subjects were studied during a walking ascent over 11 days to $4846 \mathrm{~m}$. Subjects had been allocated randomly to placebo or acetazolamide $500 \mathrm{mg} /$ day. ${ }^{4}$

Breath holding was timed from the end of a normal expiration, with no prior hyperventilation. In all tests three measurements were made by each subject. As far as possible the study was conducted with the subjects in the same position and at the same time each day, namely seated and before the evening meal. No one was tested immediately after violent physical exercise. The results were analysed using the Wilcoxon signed rank test. Acute mountain sickness was assessed by peer review. ${ }^{5}$

Correspondence: J.H. Coote D.Sc., Ph.D.

\section{Results}

The mean and longest breath holding time for each treatment group related to altitude is shown in Figure 1. For both groups breath holding time decreased with increasing altitude.

The pattern of change was different in the two groups. In the initial phase of the ascent the time fell rapidly in the placebo group but thereafter more slowly, compared with a steady decline throughout the ascent in the acetazolamide group. However, the differences were statistically significant only at 1099 and $1801 \mathrm{~m}(P<0.01)$.

There was no correlation between breath holding time at any altitude and the peer review ranking of acute mountain sickness.

\section{Discussion}

Patrick \& $\operatorname{Read}^{6}$ postulated a threshold for $\mathrm{CO}_{2}$ which influences breath holding in much the same way as it does in normal respiration. Our data cannot be explained on this basis since the placebo group were relatively hypercapnoeic throughout. ${ }^{7}$ In addition they were hypoxic compared with the acetazolamide group.

Mithoefer ${ }^{8}$ showed that by reducing the initial lung volume, breath holding time was shortened. We did not measure the expired volume to standardize the end expiratory point but each subject was tested three times in the same posture. It is probable that the variation in these repeated measurements can be explained on the basis of variation in the initial lung volumes.

This test was not popular. In view of this, motivation may have been important, although it should be 


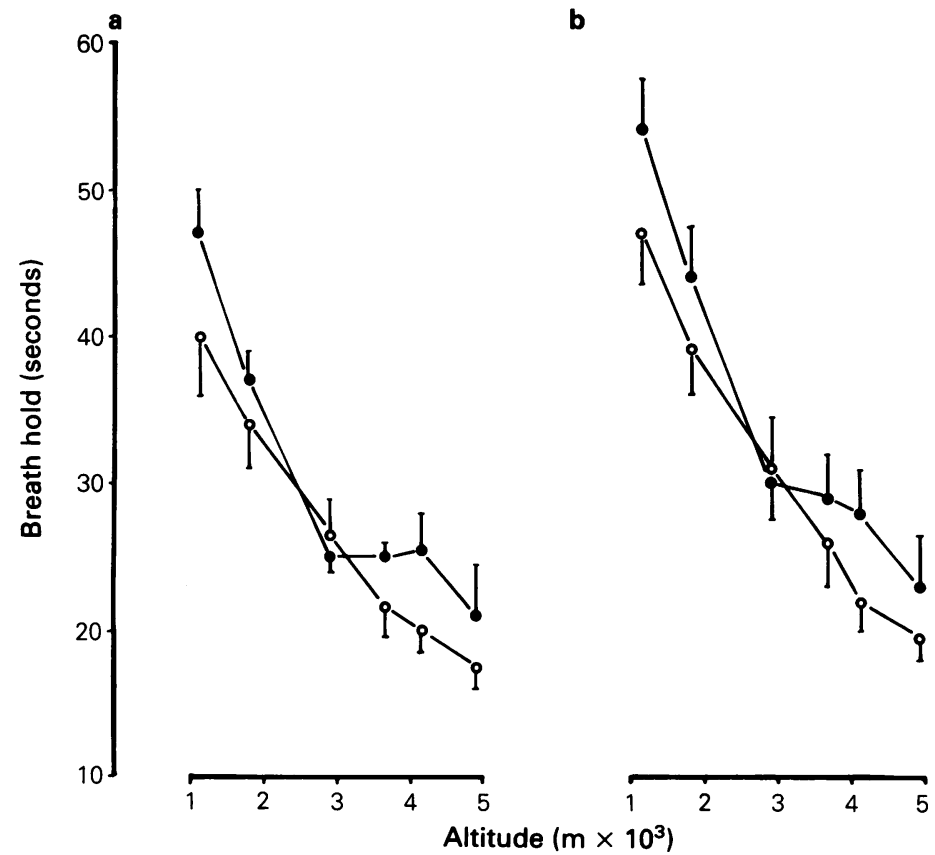

Figure 1 The mean (a) and longest (b) breath holding times at different altitudes during ascent in subjects on acetazolamide $(O)$ or placebo $(\mathbf{O})$. Mean \pm s.e.m.

noted that the results of the longest breath holding times closely mirror the mean results. If individual effort had significantly affected the results one would expect the acetazolamide group, who felt better, to have held their breaths longer but this did not happen. The longest breath holding times probably correspond more closely to each individual's true 'breaking point'.

Acetazolamide acts on the proximal tubule blocking bicarbonate reabsorption and leading to a relative

\section{References}

1. Schneider, E.C. Respiration at high altitudes. Yale J Biol Med 1932, 4: 537-550.

2. Godfrey, S. \& Campbell, E.J.M. The control of breath holding Respir Physiol 1968, 5: 385-400.

3. Birmingham Medical Research Expeditionary Society Acetazolamide in the control of acute mountain sickness. Lancet 1981, i: 180-183.

4. Bradwell, A.R. \& Coote, J.H. The BMRES 1984 Medical Research Expedition to the Himalayas. Postgrad Med J 1987, 63: 165-167.

5. Fletcher, R.F., Wright, A.D., Jones, G.T. \& Bradwell, A.R. The clinical assessment of acute mountain sickness. Q J Med 1985, 54: 91-100. acidosis. Also it blocks the production of bicarbonate by the choroid plexus leading to a lowering of the buffering capacity of the cerebrospinal fluid (CSF). The difference between the two treatment groups at $\mathrm{O}$ lower altitudes in breath holding may have been due to $\Omega$ the effect of low CSF pH directly stimulating the respiratory centre in subjects on acetazolamide causing the shorter breath holding time.

6. Patrick, J.M. \& Reed, J.W. The interaction of stimuli to breathing during breath-holding. J. Physiol (Lond) 1969 , 203: 76P.

7. Milles, J.J., Chesner, I.M., Oldfield, S., \& Bradwell, A.R. Effect of acetazolamide on blood gases and 2, 3 DPG during ascent and acclimatization to high altitude. Postgrad Med J 1987, 63, 183-184.

8. Mithoefer, J.C. Mechanism of pulmonary gas exchange $N$ and $\mathrm{CO}_{2}$ transport during breath holding. $J$ Appl Physiol N 1959, 14: 706-710. 